\title{
RICHARD EDWARDS
}

\section{"COMPLEX GLOBAL PROBLEMS, SIMPLE LIFELONG LEARNING SOLUTIONS.” DISCUSS}

The crucial philosophical question pertaining to reality was; how can we be sure? Now, after the turn to practice, we confront another question; how to live with doubt? (Mol 2002, p. 165, emphasis in original)

\section{INTRODUCTION}

Complexity theory has emerged in the sciences as a way of explaining the patterning in nature, which cannot be readily explained through traditional notions of cause and effect. A similar theoretical innovation can be found in the social sciences in the line of writing variously identified as actor-network theory (ANT), a sociology of associations or material semiotics (Latour, 2005; Law, 2007). In the latter, society is not seen as a pre-existing object of enquiry, but emerges through enactments of various forms of association, including those associated by research. Here the social is viewed as assembled in analogous ways to the manner in which in complexity theory the natural emerges. There is thus a relatedness in these perspectives, although one focuses on the natural and the other on the social.

What distinguishes ANT from complexity theory is that the social and natural are viewed as only becoming so through particular enactments of "purification" (Latour, 1993). Latour identifies purification as acts that seek to create an identity on the basis of exclusions, which work to generate knowledge on the basis of separation. The social only becomes possible through its own enactment as a separate domain. In ANT, ontology, the real, is performed and multiple rather than foundational and unitary. In complexity theory, it is arguable that there is still a foundational ontology of nature from which things emerge. Emergence is discovered as an aspect of nature rather than it being enacted.

Both complexity theory and ANT have been taken up by educational researchers (e.g., Davis et al., 2000; Haggis, 2007; Fenwick \& Edwards, 2010), but they remain marginal to the mainstream of research and theory in education. Amongst those exploring complexity theory in education, Osberg \& Biesta (2007) have argued that it points to the fundamental unpredictability of the real, and thus to the ways in which educational practices cannot be controlled or mastered. In a Freudian sense therefore, education becomes an impossible practice as it cannot mandate (Edwards, 2008). For them, complexity theory is linked to a series of theoretical innovations that suggest a more contingent engagement with the world based on impossibility, undecidability and responsibility. This is inscribed in the 
concept of strong emergence (Osberg \& Biesta, 2007). Similarly, Fenwick and Edwards (2010) point to the ways in which ANT both helps us trace the durability yet instability of educational practices, once again pointing to the question of the responsibility educators have for what we do.

Complexity theory is part of that range of framings that look at relations, interactions and networks as crucial to change. The logic of complexity suggests that the more links or feedback loops, the more recursive the system, the more potential there is for indeterminacy. Change will occur but in unpredictable if patterned ways. We witness in education practices that are very predictable at a systems level. For instance, attainment is marked by systematic effects of gender, class and race. Osberg \& Biesta (2007) argue that such predictability arises from the work of "complexity reduction," whereby recursivity and emergence are reduced. Thus, a predictability at the macro level is built into attainment by students increasingly being channelled through standardised forms of assessment, through which the range of possible markers of attainment are reduced. Standardisation entails fewer links and, with that, less recursiveness and indeterminancy. Complexity reduction is a concept that not all complexity theorists would acept, but seem useful in the examination of educational practices.

This notion of complexity reduction can be seen to be similar to the notion of black-boxing or naturalisation in ANT, wherein actors-which are themselves assemblages of animate and inanimate objects - temporarily lose their relational moorings and seem to have an independent existence. "Naturalisation means stripping away the contingencies of an object's creation and its situated nature. A naturalised object has lost its anthropological strangeness" (Bowker \& Star 1999, p. 299). The concept of "naturalisation" refers to the outcome of purification insofar as an object becomes taken for granted rather than viewed as the result of ongoing enactments. While complexity reduction may work to increase the predictability of practices, naturalisation enables networks to practice as actors and to become stabilised and durable. It is therefore possible to draw a relationship between the idea of complexity reduction and the work of purification in enabling durability and stability to be achieved if only "for the moment." The difference lies in the idea of complexity reduction being a "natural" ontology applied to the "social" or "educational," while ANT deconstructs such foundational assumptions to trace the multiple ontologies at play in enacting the social.

In this chapter I intend to explore aspects of complexity theory and ANT for our understanding of education. In particular, I want to focus on the concept of lifelong learning as an educational idea and the ways in which it is positioned in certain policy contexts as a response to the challenges of the future, as a means through which to master the uncertainty posited as inherent as we move forward in linear time. Both complexity theory and ANT point to the impossibility of such mastery, as the future is either emergence or still to be enacted at the moment at which it becomes the present. Here the impossible is that which precisely cannot be foreseen, but only glimpsed (Edwards \& Usher, 2008), prior to its enactment, its actual emergence. This is analogous to Derrida's (1992a) notion of deconstruction as "the experience of the impossible." The impossible is that which cannot be 
foreseen prior to its invention, its actual appearance. To act responsibly therefore is to accept this incalculability to the future, our inability to mandate, and invent on that basis. To not do so, to subsume one's actions to a rationale of thinking that we do know what will happen in the future, is to act irresponsibly. Undecidability is precisely the basis for a requirement to act responsibly. Complexity theory and ANT would both appear to offer the possibility of arguing for acting responsibly in what we do (Fenwick, 2009).

To act responsibly therefore would seem to involve accepting this incalculability to the future, our inability to master, and to invent on this basis. To not do so, to subsume one's actions to a rationale of thinking that we do know what will happen in the future, that it can be engineered, is to act irresponsibly. Contingency does not dissolve into a relativist view of "anything goes" but precisely into responsible encounters with what might be possible. Here caution is necessary as invention is not the opposite of complexity reduction and naturalisation. It does not simply entail enacting more relationships. It is rather that invention entails a different configuration of relationship - of recursivity and reduction in complexity terms, and of purification and translation in ANT terms. Here translation "creates mixtures between entirely new types of beings, hybrids of nature and culture" (Latour, 1993, p. 10), precisely challenging the separation work of purification. Here also the "and" is significant, as I shall return to later in the chapter.

What then of lifelong learning? I shall argue that the attempts to master the future through educational policies of lifelong learning, to reduce the complexity of the world to a particular framing of education, to purify education as lifelong learning, precisely deny the forms of responsibility that are necessary to address the undecidabilities that are being faced. I will argue that lifelong learning, as a policy, is an example of the attempt to master the future through complexity reduction in one framing and purification in another. However, I will also argue that lifelong learning as a concept deconstructs that very possibility by escaping the boundaries of the very reductions and purifications to which it is subject. Here I will suggest that inherent in the discourse of lifelong learning is the rhizomatic logic of the "and" (Deleuze \& Guattari, 2003), in particular, the notion that language stutters. It is in such stutterings that responsibility becomes possible, based not upon the assertion of certain moral orders, but on the specific contingencies faced. In other words, lifelong learning cannot be subject simply to complexity reduction and purification, as emergence and invention and responsibility are immanent within it and are there to be enacted as much through recursiveness and translation.

\section{LIFELONG LEARNING}

In education we are familiar with the desire for predictability and the capacity to master or mandate the future. At the heart of much educational policy making in Europe in recent years are attempts at mastery of the future, of the knowledge economy and social inclusion, with lifelong learning positioned as the means to achieve these. The obligatory passage point for education policy becomes the 


\section{RICHARD EDWARDS}

knowledge economy and education in the form of lifelong learning is duly harnessed and reduced to service its production. It is through the uptake of lifelong learning to support the knowledge economy that the future can be mastered and complexity reduced. Here lifelong learning is the service response to global complexity. The more challenges and uncertainty in the world, the more one must learn. It's as simple as that. But is it?

Mastery of the subject in the many senses of that concept is a key educational goal. Mastery represents a form of completion, an end to learning. However, even as it points to a position of finality and closure, we can point to the oppositions to and incompleteness to which it is subject. Mastery of the subject and subjects and self-mastery themselves become subject to incredulity. There is an incredulity as to the possibility of mastering and mandating, even as ever greater attempts are made to legislate, regulate, audit, discipline and administer (Strathern, 2000). Thus, the attempts at mastery-increasingly inscribed in discourses of standards and targets, and the accounts of accountability - only point to the inability to master. And, as

| Bowker \& Star (19992000) argue, standardisation also creates monsters insofar as not everyone fits the standard. Attempts at mastery merely bring forth more deviancy and deviants.

This search for mastery has within its margins a lack of mastery. The possibilities for lifelong learning in this sense are impossible. For lifelong learning does not remedy this lack of mastery, but actually accentuates it further. So the lack of mastery creates the conditions for the endlessness of lifelong learning. Thus, rather than being a solution to the problem of change and uncertainty-a condition for mastery and completion-lifelong learning can be therefore understood differently - as actually fuelling the uncertainty to which it is the supposed response. It entails both reduction and emergence, the possibilities for invention. It is therefore argued that rather than a route to mastery, lifelong learning might be better considered a condition of constant apprenticeship (Rikowski, 1999) or emergence. Similarly, in ANT terms, we might say that lifelong learning as apprenticeship entails constant translation. This occurs because learning as a lifelong and lifewide phenomenon is a set of uncontrollable relations, which can neither be fully reduced nor naturalised. Here learning is a flux that can only be temporarily stabilised based upon specific enactments of what is considered worthwhile. Lifelong learning is therefore as much a contributor to global complexity and the translations of the global in addition to being a reductive and purified response to it.

Lifelong learning as a policy goal therefore deconstructs the mastery through which it is so often invoked. It is in educational terms an expression of the impossibility of mastery, of mandating the future, even as it is invoked as the basis for continuing to master. Lifelong learning is symptomatic of the impossibility of education as a fully regulated practice, the response to which, in policy terms, is often the attempt to regulate and standardise further, to value only certain types and forms of relating. Its multiplicity-what some refer to as its conceptual slipperiness - cannot be reduced to the service of the knowledge economy nor social inclusion. It cannot be fully naturalised due to the monsters and deviancies it 
evokes. There is a constant play of emergence and invention, of translation, a play of disordering in the attempted orderings of education. In complexity terms, this is a naturally occurring phenomenon. In ANT terms, it arises from its multiple enactments (Mol, 2002).

However, this is too simple and perhaps comforting. The reduced concept of lifelong learning erupts because of the possibilities for emergence immanent within it. Lifelong learning can never be fully purified because of the translations to which it is subject and the multiple enactments that are possible. These are seductive discourses and ones that play upon a wider metaphorical complex familiar in education. The latter tend to enact learning as a journey, involving movement of some sort or another (Edwards et al., 2004). It is perhaps inherent in the notion of learning as change. The connotations of this notion of learning as journey are in some ways consistent with the metaphor of emergence, and the associated idea of invention, and that of translation. It links to the future as the frontier, then new, the horizon. It has a certain attractiveness to educators and to others, because of the privileging of change over continuity in modern orders. The new is good and lifelong learning is always capable of being renewed through emergence and translation.

This however, from an educational perspective, does not take account of the ways in which institutionalised learning can also be viewed as a form of reduction and purification. Institutionalised learning entails a curriculum and a curriculum is a "valued" selection from all that is possible to engage with and learn. So here learning might precisely be taken to entail complexity reduction and purification in order to be possible. Although referring to different things, cutting the network (Strathern, 1996) in ANT terms or reducing recursiveness in complexity terms both enable the stabilisations and continuities associated with a curriculum-based learning. Each requires the reduction of relations and recursiveness in order to achieve this goal.

So, we have the notion of lifelong learning as both reduction and mastery, and emergent and inventive, and purified and translated, and continuous and changing-multiple. We are not in the realm of either-or logic, but in the deterritorialisation associated with the logic of and. If the particular conjoinings and enactments of and that bring particular forms of lifelong learning into presence. To explore the line of flight through which this becomes possible, we need to make language stammer.

\section{AND...AND...AND... A STAMMERING ARGUMENT}

Here I am drawing loosely from some of the work of Deleuze \& Guattari (2003) in order to extend my discussion further. Central to their work is an effort to undermine foundational and fixed views of language and meaning associated with such pervasive arboreal metaphors as the "tree of knowledge." This foundationalism provides the basis for a view that knowledge can grow and be secure, located, wherein language can represent that which exists. The arboreal 
metaphors suggest a logical hierarchy of root, trunk, branch, twig. At one level, all is ordered, all is rooted, all is reduced, all is purified. The world can be represented.

However, as Deleuze says in his interview with Foucault (1997, p. 206-7), "representation no longer exists; there's only action-theoretical action and practical action which serve as relays and form networks." Once again, we are in the terrain of relationships and networks familiar to those drawing upon complexity theory and ANT. However, we also have to return to the differences between the two I mentioned earlier, for it can be argued that while ANT would be in line with the view that representation no longer exists, the foundationalism within complexity theory suggests representation is still possible. Knowledge is still possible in complexity theory but on different grounds to that associated with cause and effect. ANT and complexity theory might then be considered cousins more than sisters.

By contrast to the dominant arboreal metaphors, Deleuze \& Guattari (2003) introduce the idea of the rhizome, thereby introducing unexpected eruptions rather than steady growth into the view of language and meaning, wherein desire plays a role in reason and experience and experimentation are privileged over interpretation.

We're tired of trees. We should stop believing in trees, roots, radicles. They've made us suffer too much. All of aborescent culture is founded on them, from biology to linguistics. Nothing is beautiful or loving or political aside from underground stems and aerial roots, adventitious growths and rhizomes. (Deleuze \& Guattari, 2003, p. 15)

Multi-directionality and entanglement are introduced into the framing of language and meaning. "Unlike trees or their roots, the rhizome connects any point to any other point, and its traits are not necessarily linked to traits of the same nature; it brings into play very different regimes of signs, and even nonsign states" (Deleuze \& Guattari, 2003, p. 21). What is significant here is the way in which that connectedness is represented. In challenging arboreal metaphors, Deleuze \& Guattari are challenging the centrality of "to be" as the way in which the world is represented. "The tree imposes the verb 'to be,' but the fabric of the rhizome is the conjunction, 'and... and... and.' This conjunction carries enough force to shake and uproot the verb "to be" (Deleuze \& Guattari, 2003, p. 25). It is important to bear in mind the play of words here, as in French "is" (est) and "and" (et) are pronounced in the same way. There is thus a playfulness in the argument, which is nonetheless serious in its intent. The conjunctive "and" here becomes integral to rhizomatic approaches which metaphorically shake the tree of knowledge. In the process, meaning is mobilised. Deleuze \& Guattari (2003, p. 25) aim to "establish a logic of the AND, overthrow ontology, do away with foundations, nullify endings and beginnings." Following this logic, complexity theory becomes another form of enactment rather than a more accurate interpretation of the ways things are.

In line with my earlier point about the importance of responsibility, what emerges from this line of thinking is a more tentative form of discourse. Rather than simply being able to say what is the case, the assertion of an authoritative 
stance on the nature of the world and the meaning of things and what should be the case, Deleuze \& Guattari (2003) argue that the "and... and... and" of the rhizome results in a certain tentativeness, a stammering.

It's easy to stammer, but making language itself stammer is a different affair, it involves placing all linguistic, and even nonlinguistic, elements in variation, both variables of expression and variables of content. A new form of redundancy. AND... AND... AND... (Deleuze \& Guattari, 2003, p. 98)

Making language stammer may seem perverse in what are often seen as more performative times. However, this is to miss the point. Even in articulate speech language can stammer in the multiple conjoinings that are possible through "and." It is language that stammers as there are always additions, not necessarily the speakers of language. Here "AND is less a conjunction than the atypical expression of all the possible conjunctions it places in continuous variation" (Deleuze \& Guattari, 2003, p. 99). While some might want to root, reduce and purify the meaning of lifelong learning, on this understanding of the "and," it is ceaselessly shaken, as there are always rhizomatic possibilities in play of what could be.

"And" therefore does all sorts of supplementing work. It involves mediation and mobilisation. It involves power. It may act as the glue between terms but one could easily end up with sticky fingers by taking it for granted and not seeing the multiple forms of mediation to which it points. In this situation, we would be brave to try and answer the question of what "is" lifelong learning. Indeed the point becomes less one of examining what is the case and more of finding what sticks. Within this logic, emergence and reduction, stabilisation and mobilisation, purification and translation, are not binaries, but rather they require and imply one another, oscillating, wavering, in-between.

\section{EMANCIPATORY IGNORANCE}

Lifelong learning as a policy goal therefore deconstructs the mastery through which it is so often invoked. It is in educational terms an expression of the impossibility of mastery, of mandating the future, even as it is invoked as the basis for continuing to master. Lifelong learning then is symptomatic of the impossibility of education. Yet Biesta (2004, p. 71) has argued that "something has been lost in the shift from the language of education to the language of learning." He views this shift as arising from a range of contradictory trends. The four he identifies are new theories of learning, postmodernism, the rise of the consumer market and the decline of the welfare state. Biesta suggests that questions of learning are educational questions and that there is a requirement to revitalise a language for education, and the for is significant as he is positioning this discourse as an aspect of action, of ordering.

He bases his argument on three interlocking principles: "trust without ground, transcendental violence and responsibility without knowledge" (Biesta, 2004, p. 76). With regard to the first, his suggestion is that learning involves the unexpected and that this entails trust because there is risk involved. His second principle 


\section{RICHARD EDWARDS}

involves challenging and confronting students-and note he does not use the notion of learners - with otherness and difference. This entails interrupting them, what he refers to as coming into presence, the possibility of openness to difference. This entails transcendental violence as it creates difficult situations, but it is only through these that coming into presence is possible. The third principle, responsibility without knowledge, is based on the notion that educators have unlimited responsibility for the subjectivities of students, but this is not based on calculation. In later work with Deborah Osberg (Osberg \& Biesta, 2007, p. 47), they suggest that "teachers are responsible both for the emergence of the world (the future) and for the emergence of human subjectivity." Here we need to bear in mind that emergence is indeterminate, in other words a responsibility based upon impossibility.

These ideas signify notions that are a far cry from any certainty about the teleological goals of education and how they are to be achieved. They are based upon processes of constant invention rather than ultimate purposes as ends. This may or may not be positioned as another reduction. And perhaps this is as it needs to be. In his critique of critical pedagogy's desire for a language of possibilitywhich itself often attempts certain reductions of possibility-Biesta (1998) extends this idea of the impossibility of mandating the future to all human interactions and suggests, drawing on Derrida and Foucault, that practices need to be developed around an "emancipatory ignorance." Here

It just is an ignorance that does not claim to know how the future will be or will have to be. It is an ignorance that does not show the way, but only issues an invitation to set out on the journey. It is an ignorance that does not say what to think of it, but only asks, "What do you think about it?" In short it is an ignorance that makes room for the possibility of disclosure. (Biesta, 1998, p. 505).

Biesta's argument is related specifically to critical pedagogy, but it is relevant to the reformulation of a discourse of education more generally. This is a call for a pedagogy of invention (Osberg \& Biesta, 2007).

Formulating an educational discourse around apprenticeship, impossibility and ignorance may seem absurd. When outcomes and outputs are to the fore, what spaces are there for educational discourses around emergence? It is here that I find the concepts of fallibility and conditionality in addition to impossibility helpful. Fallibility because it points to the notion that, even if we practice upon the basis of the best available evidence we have, we know full well it is not perfect, that we cannot mandate. This is turn results in and from a position of conditionality, that is, we could do something rather than we should do something. Our efforts then are only as good as we currently can establish and they are a process of invention, emergence and reduction, rather than any exercise in mandating and mastery. The normative basis for what we do becomes a more cautiously creative affair, something which may seem unattractive to many educators who feel the normative potential of education to transform people and societies is unrealised. Fallibility and conditionality provide a basis for invention, for creativity and experimentation 
in educational practices, based upon impossible possibilities. However, for this to be other than an "anything goes" approach to education, we now need to address the question of responsibility.

It is in this spirit that I think Gert Biesta's (2006, p. 68) suggestion that we adopt an approach of "responsibility without knowledge" seems to have resonance; This "the responsibility of the educator, the educational responsibility, is a responsibility for something that cannot be known in advance-it is a responsibility without knowledge of what one is responsible for".

requires that we give up, or at least hold back, all the "tricks of the trade," all the wisdom of the world, all national curricula and educational strategies, all recipes for "what works," in order to be able to approach newcomers without an agenda or pre conception, but in a way in which we can ask them what they are bringing to the world. It is in this way that educators take a responsibility for something that they cannot know. It is a responsibility without knowledge. (Biesta, quoted in Fenwick, 2009).

Biesta is drawing upon Derrida. Here "the condition of this thing called responsibility is a certain experience and experiment of the possibility of the impossible: the testing of the aporia from which one may invent the only possible invention, the impossible invention" (Derrida, 1992b, p. 41). Invention is not based in the tension in the impossibility of mandating the future. And Fenwick $(2009, \mathrm{p}$. 116 ), who is explicitly exploring issues of educational responsibility in response to complexity theory, equally suggests that "educators might think of doing less rather than more: focus on the immediate, open to possibility, leap into uncertainty, care without knowledge.",

Complexity reduction and purification may be necessary features of the ordering of associations for the social to be possible at all. And indeed, Deleuze \& Guattari (2003) suggest that the aboreal and the rhizome are both integral to meaning making, despite their apparent disdain for the aboreal. It may therefore be responsible for us to decrease recusivity in certain circumstances, to try and make the impossible possible, at least for the moment. This view seems to rely precisely on the forms of conditionality and fallibility I have suggeted. It positions complexity reduction to be important and valuable in making things happen, even if it is also subject to the invention of emergence.

What I am suggesting here then, is that it is not about invoking either possibility or impossibility, emergence or reduction, invention or performativity, purification or translation, but about trying to formulate ethical orderings within which there is an inherent play of (un)predictability, in which we replace "or" with "and" and feel language stutter. For me, however unsatisfactory, the concept of lifelong learning symbolises an educational expression of this condition, precisely because it opens up the question of what is worthwhile rather than seeking to "solve" the issue of what constitutes good or effective education.

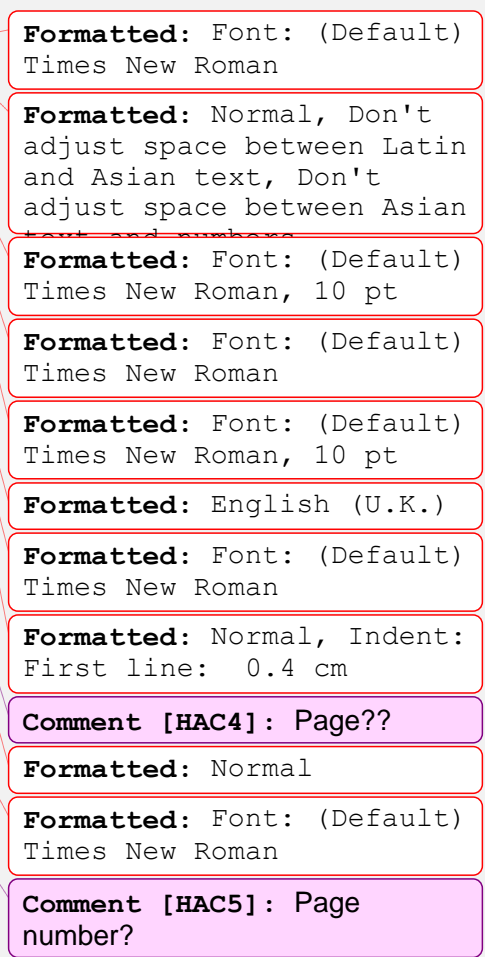


RICHARD EDWARDS

\section{(IN)CONCLUSION}

Fallibility, conditionality and responsibility. These seem to be ways forward from the notion of education as an impossible practice. They open up possibilities of course, but not on the notion of mandating the future or any fundamentalist enthusiasm about what education can achieve or how it can achieve. They put us all in a position of apprenticeship, whether we are engaged in policy work, teaching, leading, or researching. And perhaps they are necessary if we are to sustain and develop modest democratic practices and the institutional practices to support them. Perhaps then some worthwhile things would be possible.

However, it is also the case that while complexity theory offers some useful insights into these issues, it remains nonetheless a foundationalist stance. I have indicated that ANT may offer equally useful insights into these issues, but that its anti-foundationalism may well present us with more radical framings. I am not suggesting that we do not explore the possibilities of complexity theory for education, as it can be a powerful discourse in performative times. What I am suggesting is that ANT offers a more consistent emancipatory ignorance in the multiple enactments of lifelong learning.

\section{ACKNOWLEDGEMENT}

My thanks to Tara Fenwick for comments on this chapter, which is a shorter version of an argument that will be published in 2010 in Pedagogy, Culture and Society.

\section{REFERENCES}

Barad, K. (2007). Meeting the universie halfway, Cambridge, Ma.: Harvard University Press

Biesta, G. (1998). Say you want a revolution.... Suggestions for the impossible future of critical pedagogy, Educational Theory, 48, 4: 499-510.

Biesta, G. (2004). Against learning: Reclaiming a language for education in an age of learning, Nordisk Pedogogik, 24, 1: 70-82.

Biesta, G. (2006). Beyond learning: Democratic education for a human future. Boulder Colorado: Paradigm Publishers.

Bowker, G. \& Star, S. (19992000). Sorting things out, Harvard: Harvard University Press.

Davis, B., Sumara, D. \& Luce-Kaplar, R. (2000). Engaging Minds: Learning and Teaching in a Complex World, Mahwah, NJ.: Lawrence Erlbaum.

Deleuze, G. \& Guattari, F. (2003). A thousand plateau, London: Athlone Press.

Derrida, J. (1992a). 'Afterwards: or, at least, less than a letter about a letter less, in N. Royle (ed) Afterwords, Tampere: Outside Books.

Derrida, J. (1992b). The other heading: Reflections on today's Europe, Bloomington: Indiana University Press.

Edwards, R. (2008). Education - an impossible practice, Scottish Education Review.

Edwards, R. \& Usher, R (2008). Globalisation and pedagogy, London: Routledge.

Edwards, R., Nicoll, K., Solomon, N. \& Usher, R. (2004). Rhetoric and educational discourse, London: Routledge. 
COMPLEX GLOBAL PROBLEMS, SIMPLE LIFELONG LEARNING SOLUTIONS

Fenwick, T. (2009). Responsibility, complexity science and education: Dilemmas and uncertain responses, Studies in Philosophy and Education, 28,2: 101-118.

Fenwick, T. \& Edwards, R (2010). Actor-network theory in education, London: Routledge

Haggis, T. (2007). Education and complexity, in J. Bogg and R. Geyer (eds) Complexity, science and society, OxfordPlace??: Radcliffe Publishers

Latour, B. (1993). We have never been modern, Cambridge, Mass.: Harvard University Press.

Latour, B. (2005). Reassembling the social, Oxford: Oxford University Press.

Law, J. (2007). Actor network theory and material semiotics. Version of $25^{\text {th }}$ April 2007, available at http://www.hetrogeneities.net/publications/Law-ANTandMaterialSemiotics.pdf. (Downloaded on 22 February 2008)

Mol, A. (2002). The body multiple, Durham: Duke University Press.

Osberg, D. \& Biesta, G. (2007). Beyond presence: epistemological and pedagogical implications of "strong" emergence, Interchange, 38, 1: 31-51.

Rikowski, G. (1999). Nietzsche, Marx and mastery: The learning unto death, in P. Ainley and H. Rainbird (Eds) Apprenticeship: Towards a new paradigm for learning, London: Kogan Page.

Strathern, M. (1996). Cutting the network, Journal of the Royal Anthropological Institute, 2, 3: 517 535 .

Strathern, M. (2000). (ed) Audit cultures: Anthropological studies in accountability, ethics and the academy, London: Routledge.

Richard Edwards

The Stirling Institute of Education,

University of Stirling, UK 